\title{
INCLUSÃO E EDUCAÇÃO FíSICA NO MUNICÍPIO DE RIO GRANDE: REFLEXÕES SOBRE AS PERCEPÇÕES DOS EDUCANDOS COM DEFICIÊNCIA
}

\author{
INCLUSION AND PHYSICAL EDUCATION IN RIO GRANDE CITY: REFLECTIONS \\ ABOUT PERCEPTIONS OF STUDENTS WITH DISABILITIES
}

INCLUSIÓN Y EDUCACIÓN FÍSICA EN LA CIUDAD DE RIO GRANDE: REFLEXIONES SOBRE LAS PERCEPCIONES DE LOS ESTUDIANTES CON DISCAPACIDAD

\section{Alice Sonaglio de Vasconcellos*, Leila Cristiane Finoquetto*, Roseli Belmonte Machado*, Débora Duarte Freitas ${ }^{\star *}$}

\begin{abstract}
Palavras-chave
Inclusão

educacional.

Pessoas com

deficiência

Educação Física

Pesquisa qualitativa.

Resumo: Este artigo tem por objetivo identificar e refletir sobre as percepções dos educandos com deficiência a respeito do seu processo de inclusão nas aulas de Educação Física na rede municipal da cidade do Rio Grande/RS. Participaram do estudo três alunos dos anos finais, que têm o acompanhamento de um monitor. Realizamos três observações, registradas em diário de campo e uma entrevista semiestruturada para cada um dos entrevistados. Para análise de dados foram criadas três categorias: mecanismos de in/exclusão, processos de vigilância e a normalização do anormal. Como ferramentas teórico-metodológicas utilizamos os Estudos Foucaultianos, principalmente os conceitos que versam sobre norma, normação e normalização. Como apontamentos desta pesquisa podemos refletir sobre o modo como os processos de inclusão se instalam como um imperativo, provocando professores e monitores a trabalharem como normatizadores e normalizadores de alunos com deficiência, os quais percebem o processo como positivo.
\end{abstract}

Keywords

Educational

inclusion. Disabled

persons. Physical

education.

Qualitative research.

Inclusión

educacional.

Personas con

discapacidad.

Educación Física.

Investigación

cualitativa.

Abstract: This article aims to identify perceptions of students with disabilities about their process of inclusion in Physical Education classes in public schools of the city of Rio Grande. Participants included three students from the final years, who were followed by monitors. Three observations recorded in a field diary and a semi-structured interview were performed for each of the respondents. Three categories were created: inclusion/ exclusion mechanisms; monitoring procedures; and normalization of the abnormal, which were analyzed based on Foucault's studies, specially concepts of norm, normation and normalization. This research looks into how inclusion processes are established as imperatives and lead teachers to work as normatizers and normalizers of students with disabilities, who perceive the process as positive.

Resumen: Ese artículo tiene por objetivo identificar y reflexionar sobre las percepciones de los educandos con deficiencia en lo que se refiere a su proceso de inclusión en las clases de Educación Física en la red pública de la ciudad de Rio Grande. Participaron del estudio tres alumnos, de los años finales, que son acompañados por un monitor. Realizamos tres observaciones, registradas en un diario de campo y una entrevista semiestructurada para cada uno de los entrevistados. Para el análisis de los datos fueron creadas tres categorías: mecanismos de in/exclusión, procesos de vigilancia y la normalización de lo anormal. Como herramientas teórico-metodológicas utilizamos los Estudios Foucaultianos, principalmente los conceptos que versan sobre norma, normatización y normalización. En esta investigación, podemos reflexionar sobre el modo en que se instalan los procesos de inclusión, como un imperativo, obligando a que profesores y monitores trabajen como normatizadores y normalizadores de estudiantes con discapacidad, que perciben el proceso como positivo.
* Universidade Federal do Rio Grande. Rio Grande, RS, Brasil.

E-mail: alice-sonaglio@bol.com.br

** Universidade Federal do Rio Grande do Sul. Porto Alegre, RS, Brasil.

E-mail: freitasdeboraduarte@gmail.com

Recebido em: 21-07-2015 Aprovado em: 23-04-2016 


\section{PARA PENSAR 0 TEMA}

O debate sobre inclusão vem crescendo significativamente no país desde a década de 1980. Fez-se presente em nossa legislação por intermédio da Conferência Mundial sobre Educação para Todos (1990), da Conferência Mundial de Educação Especial (1994), da Lei de Diretrizes e Bases da Educação (1996), da Lei de Acessibilidade (2004), dentre outros. Promovido a partir das discussões de direito das minorias, esse tema passou a ser refletido por inúmeros autores. Numa perspectiva pós-estruturalista de debater a educação, na qual nos inserimos, autores como Lopes (2009; 2011; 2013), Lopes e Fabris (2013), Thoma e Hillesheim (2011), Lockmann (2010), Santos (2010) e Veiga-Neto (2001) têm trazido importantes reflexões sobre a temática. Além disso, a discussão sobre inclusão também está presente nas agendas das Secretarias do Ministério de Educação (2013); nas discussões nas escolas e tem grande visibilidade nos programas e veículos de informação.

Como professoras envolvidas com a inclusão e com a Educação Física Escolar, notamos que esse tema, ao atravessar o campo educacional e social, também atravessa as aulas de Educação Física. Nesse escopo, este trabalho versará sobre as aulas de Educação Física e a inclusão de alunos com deficiência, estabelecendo uma problematização desse tema, sem enaltecê-lo ou condená-lo, mas discutindo algumas verdades que são dadas como naturais em torno da inclusão. Conforme aponta Santos (2010):

Pensar e problematizar a inclusão ou pensar qualquer outro tema que foi inventado em uma atmosfera moderna para democratizar acessos, para "garantir" igualdade a todos, é entendido muitas vezes como um movimento de direita ou como um movimento de oposição à inclusão (SANTOS, 2010 p. 10).

Dessa forma, trabalhamos com a ideia de que as verdades produzidas sobre inclusão na sociedade em que vivemos, além de serem pensadas por aqueles considerados normais ${ }^{1}$, são construídas historicamente. Para Foucault (1988) a verdade é deste mundo e é produzida graças a múltiplas coerções e nele produz efeitos regulamentados de poder. Assim, cada sociedade tem seu regime de verdade, ou seja, os tipos de discursos que ela acolhe e faz funcionar como verdadeiros, assim como as técnicas e procedimentos que são valorizados.

Desse modo, pensamos ser muito profícuo problematizar a inclusão dada como uma verdade, já que esta é um produto da sociedade, podendo inclusive sustentar alguns processos de exclusão. Temos notado, por exemplo, que as aulas de Educação Física, em diversas escolas, têm retratado muito desse movimento que ora inclui e ora exclui os sujeitos. Para dar corpo a nossa discussão, buscamos neste trabalho discutir a construção dessa verdade sobre a inclusão, a qual a identifica como algo benevolente e bom para todos, por uma sociedade de normais, procurando dar voz a educandos com deficiência que estão incluídos em aulas de Educação Física. Essa verdade sobre inclusão a qual nos referimos é a disseminação de discursos que identificam esse ato como algo simplesmente benéfico sem aprofundar a discussão sobre a realidade dos alunos e das escolas; a proliferação de manuais, técnicas e estratégias que são vistos como os salvadores da escola e da inclusão e não discutem o que serve para quem, desconsiderando, muitas vezes, a diversidade dos sujeitos. Como já citamos, nossa linha de problematização dessas verdades encontra apoio nos trabalhos de estudiosos que debatem sobre o tema com base nos Estudos Foucaultianos. Nessa esteira de pensamento, este

1 Em breve iremos explorar a discussão de normais e anormais quando tratarmos sobre norma e os processos de normação e normalização. 
trabalho tem por objetivo identificar as percepções dos educandos com deficiência a respeito do seu processo de inclusão nas aulas de Educação Física na rede municipal da cidade do Rio Grande/RS. Acreditamos que essa é uma problematização interessante, pois levanta dados que nos fazem refletir sobre a inclusão e as aulas de Educação Física nesse município, nos fornecendo informações que ainda não estão em circulação. Dar voz aos alunos e ouvir suas considerações sobre esse processo que por vezes os assujeita talvez seja um dos modos de fazer diferente a própria inclusão.

Neste artigo estamos trazendo os resultados desta nossa pesquisa. Para melhor organizar nossas considerações, os dividimos em quatro etapas. Na primeira são detalhados os procedimentos metodológicos, desde a aproximação com a escola e os alunos até a finalização e interpretação dos dados. Na segunda explicitamos alguns conceitos-ferramentas importantes para o entendimento da perspectiva de onde olhamos a inclusão, sendo eles: norma, normação, normalização. Na terceira etapa são apresentados os resultados e discussões do trabalho. Logo após, a partir do que foi desenvolvido, trazemos nossas considerações finais.

\section{OS CAMINHOS DA PESQUISA}

Inicialmente, destacamos que esse trabalho traz um desafio bastante interessante, que é o de pensar a inclusão através da perspectiva daqueles que são os sujeitos desse processo os alunos em processo de inclusão. Nesta pesquisa, nos filiamos à determinação estabelecida pelo município de Rio Grande que nomeia como alunos em processo de inclusão aqueles alunos com deficiência inseridos nas turmas regulares que, para a efetivação de sua inclusão, recebem um monitor para auxiliar como mediador nesse processo. Segundo Veiga-Neto (2007, p. 111), "[...] nos tornamos sujeitos pelos modos de investigação, pelas práticas divisórias e pelos modos de transformação que os outros aplicam sobre nós mesmos". Nesse contexto, segundo o autor, Foucault tomou a palavra "sujeito" pelos seus dois significados mais importantes: "[...] sujeito [assujeitado] a alguém pelo controle e dependência, e preso à sua própria identidade por uma consciência ou autoconhecimento" (VEIGA-NETO, 2007, p. 136).

De um modo geral, a maioria das políticas públicas e as ações voltadas aos educandos com deficiência são feitas por sujeitos considerados normais. Contudo, em nosso trabalho, optamos por dar voz aos sujeitos que são avaliados como "anormais" ${ }^{2}$, ouvindo os alunos com deficiência. Para isso, realizamos entrevistas semiestruturadas com esses educandos e observamos suas aulas de Educação Física, registrando nossas impressões em um diário de campo.

A entrevista realizada com os alunos foi composta por perguntas que os remetiam a refletir sobre as aulas de Educação Física, sobre o seu o relacionamento com os colegas, a respeito do monitor que os acompanha e de seu professor. Entendemos a entrevista como um ambiente com muitas possibilidades e significados, o que é corroborado por Silveira (2007), que considera a entrevista como uma arena de significados.

[...] 0 entrevistador se torna cúmplice ou, decididamente, uma espécie de inquisitor, mas o enquadramento inicial do que "vai acontecer" é imprescindível. E é nesse terreno movediço entre o esperado e 0 inesperado, entre a repetição e a inovação, que resvalam as entrevistas (SILVEIRA, 2007, p. 124).

20 uso dos termos normal e anormal é uma escolha feita a partir da perspectiva de pesquisa dos estudos foucaultianos, na qual são posicionados como normais e anormais aqueles que sofreram processos de normação e normalização. Esses processos serão explicados com detalhes na seção 3 deste trabalho. 
Para a seleção dos estudantes que seriam entrevistados, estabelecemos alguns critérios: serem alunos da rede pública municipal da cidade do Rio Grande/RS com o acompanhamento de um monitor - chamados de alunos em processo de inclusão; estarem entre 0 6ำ e 0 9o ano do Ensino Fundamental; e terem professor de Educação Física. Após o levantamento dos dados de alunos junto à Secretaria Municipal de Educação do Município de Rio Grande/ $\mathrm{RS}$, concluímos que três alunos atenderam a esses critérios. Esses alunos em processo de inclusão pertenciam a escolas diferentes e bairros distintos e foram nomeados como alunos $A$, $\mathrm{B}$ e C. Por se tratarem de alunos menores de idade, os pais ou responsáveis pelos alunos e a direção da escola assinaram um Termo de Consentimento Livre e Esclarecido autorizando 0 trabalho. A cada aluno foi explicado o processo da entrevista e pedido seu consentimento de forma oral. Após a realização das entrevistas, elas foram transcritas e passaram a compor a materialidade de nossa pesquisa.

Além desse material, também utilizamos em nossas análises o material presente no Diário de Campo. Este foi constituído por três observações de aulas de Educação Física para cada entrevistado, em dias distintos, as quais antecederam a entrevista com a intenção de conhecer 0 aluno com deficiência, o considerado anormal, os seus colegas, a aula de Educação Física, o monitor, o(a) professor(a) de Educação Física e criar um ambiente ameno para a entrevista.

Para refletir sobre a materialidade obtida nas entrevistas e no Diário de Campo, utilizamos os conceitos dos Estudos Foucaultianos, pois nos ajudaram a problematizar as respostas dos educandos. Dentre as possibilidades que se apresentavam, optamos por utilizar como ferramentas teórico-metodológicas os conceitos de norma, normação e normalização. Após uma minuciosa análise das entrevistas e do material do Diário de Campo, com base nos conceitos dos Estudos Foucaultianos, organizamos o material em três categorias distintas: mecanismos de in/exclusão, processo de vigilância do considerado anormal e a normalização do considerado anormal. No item 4 detalharemos cada uma delas.

\section{UM OLHAR PARA A INCLUSÃO}

Nesta pesquisa nos aliamos a uma perspectiva e a autores que questionam a inclusão como um imperativo e como estatuto de verdade. Desse modo também a problematizamos como uma prática vista como boa para todos. Para além disso, entendemos a inclusão como uma forma de aproximar os sujeitos para conhecê-los e, de certo modo, melhor conduzi-los e governá-los. Segundo Lockmann (2010, p. 67), "a inclusão aproxima os sujeitos da sociedade para constituí-los como uma população que tem suas singularidades, seus riscos próprios, suas ameaças, mas que, estando perto e sendo conhecido, pode ser controlado e governado".

Pelos processos de inclusão passamos a estabelecer um conhecimento sobre o outro. Como afirma Santos (2010), devemos refletir sobre a inclusão "[...] como uma operação de ordenamento que fixa quem somos nós e quem são os outros, assim como procura capturar os perigosos, os estranhos. Ao me aproximar desse outro, acabo estabelecendo um saber sobre ele" (SANTOS, 2010, p. 101). Esse saber que estabelecemos sobre o outro vem atrelado ao entendimento de norma que identifica e nomeia o normal e 0 anormal. 
Nesse processo de individualizar e, ao mesmo tempo, remeter ao conjunto, dão-se as comparações horizontais - entre os elementos individuais - e verticais - entre cada elemento e o conjunto. E ao se fazer isso, chama-se de anormal aqueles cuja diferença em relação à maioria se convencionou ser excessivo, insuportável. Tal diferença passa a ser considerada um desvio, isso é, algo indesejável porque des-via, tira do rumo, leva à perdição (VEIGA-NETO, 2007, p. 75).

Dessa forma, ao se estabelecer uma norma, é permitida uma comparação e uma diferenciação entre os indivíduos. Na Sociedade Disciplinar e na Sociedade de Segurança descritas por Foucault, a norma funcionou de maneira diferente. Numa descrição breve, podemos dizer que a disciplina - marca de uma Sociedade Disciplinar (FOUCAULT, 2007) - é essencialmente centrípeta, ela centra nela mesma e encerra. Tem por objetivo regulamentar tudo sem deixar escapar nada. Ela procede dividindo todas as coisas de acordo com um código binário. Já os dispositivos de segurança - típicos da Sociedade de Segurança (FOUCAULT, 2008) tendem perpetuamente a ampliar, são centrífugos. Articulam-se a dados estatísticos a partir de curvas de normalidades e intervêm de maneira que trabalhem em cima de um convencimento $e$ não a partir da negação. $O$ processo em relação à norma na Sociedade Disciplinar é chamado normação e, segundo Foucault (2008),

[...] consiste em primeiro colocar um modelo, um modelo ótimo que é construído em função de certo resultado, e a operação de normalização disciplinar consiste em procurar tornar as pessoas, os gestos, os atos, conformes a esse modelo, sendo normal, precisamente quem é capaz de se conformar a essa norma e o anormal quem não é capaz. Em outros termos, o que é fundamental e primeiro na normalização disciplinar não é o normal e o anormal, é a norma (FOUCAULT, 2008, p. 75).

Já na Sociedade de Segurança, a norma opera em processos de normalização. Esta não é fixa, pois ela é estabelecida através das características daquela sociedade. Lopes e Fabris (2013) comentam que a norma de seguridade ou de normalização é constituída a partir do normal que é determinado no interior das comunidades e/ou grupos sociais. Isso significa que primeiro está dada a normalidade dos grupos para depois ser estabelecido o normal para ele. Portanto, a normalidade, na Sociedade de Segurança, tem fronteiras frágeis, maleáveis e negociáveis de acordo com os desejos dos sujeitos e dos grupos que eles integram.

Ainda segundo Lopes e Fabris (2013), a norma age de forma prescritiva, provocando ações que homogeneízem as pessoas, ou ainda, provocando ações que exaltem as diferenças a partir de referenciais comunitários. Essa exaltação da diferença é bastante percebida nos discursos atuais de inclusão, uma vez que se tornou quase um crime se posicionar contra a inclusão ou não ter um discurso ou opinião formada a esse respeito e, quando esta avaliação é feita, deve ser de inclinação positiva. Entendemos que essa exaltação vem atrelada ao imperativo da inclusão (LOPES, 2011), ou seja, a inclusão dada como algo que é bom e que todos devem cumprir, sem contestar.

Além disso, ressaltamos que a norma através de processos de normatização e normalização age diretamente nas instituições. Através de mecanismos normalizadores a escola procura conduzir a conduta dos anormais para o mais próximo da normalidade possível. A inclusão é uma estratégia importante de condução e deve atingir a todos sem distinção e independente dos desejos dos indivíduos. Ao entendermos a inclusão como um imperativo, passamos a refletir sobre a relação do normal com o anormal. Entendendo esse último como o outro, o excluído, o estranho, aquele a quem devemos respeitar e exaltar sua diferença, mas 
de maneira alguma ser parecido.

No entanto, não é só o anormal que sofre a exclusão, mas também o normal, pois vivemos em processos de in/exclusão. Esse termo, segundo Lopes e Fabris (2013) enfatiza "[...] a complementaridade dos termos ou a sua interdependência para a caracterização daqueles que, mesmo vivendo em situação de rua, de cárcere, de discriminação negativa [...] não podem ser apontados como excluídos" (LOPES; FABRIS, 2013, p.10). Isso significa que em alguns momentos estaremos incluídos e, em outros, excluídos. Como afirmam Veiga-Neto e Lopes:

\footnotetext{
Dizer que ninguém é, per se, um incluído ou excluído significa duas coisas que se superpõem. A primeira: é na relação que alguém mantém com os demais que ele poderá ser considerado um excluído ou um incluído. A segunda, tão importante quanto a anterior: a inclusão não é uma "coisa" que exista por si mesma; do mesmo modo, ser um incluído ou excluído não é definido por alguma condição ou princípio que preexista às próprias práticas que definem a inclusão (VEIGA-NETO; LOPES, 2011, p.9).
}

Com isso, não estamos afirmando que as diferenças entre os sujeitos normais e os anormais não existam, mas, sim, apontando que não há uma relação de completa exclusão e/ ou inclusão. 0 que temos são mecanismos que se justapõem, fazendo com que o sujeito se encontre em diferentes posições de acordo com determinadas situações.

No âmbito da Educação Física e no desenvolvimento de atividades esportivas para pessoas com deficiência, também é possível ver essa prática que, apesar de se nomear como includente, ora exclui e ora inclui. Trabalhos como os de Machado (2011), que comparam as Olimpíadas e as Paralimpíadas através da fala de atletas paralímpicos, evidenciam que mesmo numa competição esportiva destinada a pessoas com deficiência, como é o caso das Paralimpíadas, a exclusão acontece. Para a autora "esses sujeitos que foram subjetivados pela lógica neoliberal são incluídos, mas não são tomados como normais. Ainda que sejam atletas, recebem outro tratamento. Para eles, ainda são destinados lugares e posições sociais diferenciadas ou de menor valor" (MACHADO, 2011, p. 135). Mandarino (2010), outro autor que discute a Educação Física nessa perspectiva a que nos filiamos, nos aponta que no contexto da escola "as experiências de conviver entre si, na escola e na Educação Física acontecerá num mesmo lugar, de dentro, em que serão ali exercidos os discursos de in/exclusão dos/as escolares" (MANDARINO, 2010, p.5). Desse modo, é possível pensar que a Educação Física, como parte da sociedade e da escola, também reverbera as verdades sobre inclusão e, junto a isso, carrega consigo os processos de in/exclusão.

\section{COM A PALAVRA O OUTRO, O CONSIDERADO ANORMAL}

Nesse espaço problematizamos as falas dos educandos com deficiência, obtidas nas entrevistas, bem como os registros do diário de campo. As informações coletadas foram organizadas em três categorias: mecanismos de in/exclusão, processo de vigilância do anormal e a normalização do anormal.

\subsection{Mecanismos de in/exclusão}

De um modo mais abrangente, a inserção do deficiente na escola é considerada um mecanismo de inclusão. Porém, analisamos que somente a ocupação de um mesmo espaço físico não garante a inclusão desse sujeito, pois não garante o acesso às atividades desenvol- 
vidas nas aulas. Dessa forma, nessa primeira categoria observamos que a inclusão dos alunos no espaço físico não é garantia de estar incluído. Essa condição foi evidenciada a partir das observações das aulas de Educação Física em que percebemos que quando havia divisões de times uma das alunas com deficiência era esquecida. A seguir, trazemos excertos das falas dos alunos e recortes dos diários de campo para compor nossa discussão.

A professora avisa que escolherá quatro alunos para fazer os times. A aluna $\mathrm{A}$ levanta a mão, mas não é vista. Reclama, mas não é escutada. Termina a escolha dos times e a professora manda as meninas para a quadra para começar o jogo, porém a Aluna A e outra colega não foram escolhidas. Quando estão para começar o jogo, uma aluna diz: "Professora, falta a Aluna A" e a professora responde: "Entra uma de cada lado" e a colega chama A para o seu time. Ela fica faceira e vai para a quadra e mostra como sabe chutar (DIÁRIO DE CAMPO, 14 maio 2014).

Outro momento que merece destaque é o da entrevista, em que a Aluna $A$, ao ser questionada sobre o seu relacionamento com os colegas durante as aulas de Educação Física, percebe-se excluída pelos demais colegas e os identifica como maus.

Pesquisadora: Durante a aula de Educação Física como é teu relacionamento com os colegas? Como os teus colegas te tratam? Como é que tu tratas eles?

Aluna A: É tudo do mal. ${ }^{3}$

Pesquisadora: Tudo do mal? Por que tudo mal?

Aluna A: É porque eles correm, correm. Jogam futebol, mas não comigo. (ENTREVISTA DA ALUNA A).

A respeito disso, a Declaração Mundial sobre Educação para todos, no artigo 3, inciso 5, comenta que:

As necessidades básicas de aprendizagem das pessoas portadoras de deficiência requerem atenção especial. É preciso tomar medidas que garantam a igualdade de acesso à educação aos portadores de todo e qualquer tipo de deficiência, como parte integrante do sistema educativo. (ORGANIZAÇÃO DAS NAÇÕES UNIDAS PARA A EDUCAÇÃO, CIÊNCIA E CULTURA, 1990).

Porém, o que observamos através do relato dos alunos e das observações das aulas é que apenas o acesso à educação e à escola regular não é suficiente para que possam ocorrer práticas inclusivas. Outro exemplo está na passagem abaixo destacada do Diário de Campo:

Nesse momento, os alunos estão livres. E um grupo de meninos joga basquete com a bola de vôlei e Aluno $B$ vai junto. Os colegas não passam a bola para ele e 0 fazem de bobo, pois ele fica correndo na volta deles para pegar a bola, mas eles 0 enganaram fazendo gestos de que vão jogar para ele, mas não jogam. Um colega ainda ri e diz: "Tem que aprender a jogar". Quando Aluno B pega a bola sai correndo com ela na mão e tenta arremessar. Todos os colegas debocham inclusive a monitora. Na busca pela bola, ele corre para tentar pegar a bola de um colega, enquanto o colega faz movimentos em círculo. Aluno $B$ desequilibra e cai no chão. Todos riem. (DIÁRIO DE CAMPO, 22 maio 2014).

Além disso, outro ponto bem interessante a respeito desses mecanismos de in/exclusão é o relato do Aluno $\mathrm{C}$, que, quando questionado sobre o seu sentimento em relação à Educação Física, expressa a compreensão de que existe ele - considerado um anormal - e os seus colegas - considerados normais.

Bem, eu me sinto bem. Me sinto. Eu fico quieto, na minha. Fico quieto na minha.

3 As falas dos alunos foram transcritas e foi observada a adequação à forma escrita, preservando o significado de suas narrativas. 
Por causa que porque ninguém vem me incomodar. Ninguém vem me incomodar. Por causa que fica todo mundo lá jogando e eu fico. Quando era no ginásio, eu ficava sentado lá. Só de vez em quando, quando era punhobol, eu jogava. (ENTREVISTA DO ALUNO C).

Vale ressaltar que não queremos afirmar a existência de somente práticas excludentes na escola, mas queremos dar visibilidade às práticas de exclusão sofridas por alunos considerados incluídos, pois muitas vezes elas não são mostradas. Na linha de divulgar a inclusão como uma verdade benéfica a todos, por vezes as práticas excludentes que ela produz ficam invisíveis. Para Veiga-Neto e Lopes (2007), embora as instituições que garantem acesso e atendimento a todos sejam includentes, elas acabam por manter quase todos ou muitos desses em situação de exclusão. Como comentamos na sessão anterior, as relações de in/exclusão não são fixas, pois em um momento estamos incluídos e em outro podemos estar excluídos. Isso não significa que essa divisão ocorra em parcelas iguais, pelo contrário, há pessoas que são muito mais excluídas do que outras.

\subsection{Processo de vigilância do considerado anormal}

Outro ponto que analisamos é o duplo processo de vigilância que sofre o aluno anormal nas escolas do município de Rio Grande. Percebemos que o anormal tem um processo de vigilância maior do que dos demais alunos, pois além do professor da disciplina que o gerencia, há o monitor para regular o seu comportamento e enquadrá-lo em atitudes consideradas adequadas. A partir disso, concordamos com Veiga-Neto e Lopes ao afirmarem que:

[...] chamamos de educadores, professores, instrutores e mestres aqueles que promovem a força do rebatimento, trazendo os outros para o mais próximo de si possivel, para a sua morada, para o seu domínio. Chamamos de educandos, alunos, aprendizes e discípulos a esses outros sobre os quais se promove e força o rebatimento, a esses outros que são trazidos para o domínio daqueles que comandam a ação do rebatimento. Em suma, pensando em termos de rebatimento, é como se, no processo de educar, os outros aqueles que se situam num plano fossem rebatidos para o plano onde já se situavam os mesmos (VEIGA-NETO; LOPES, 2011, p. 3).

Diante disso, lembramos que a escola é pautada por um mecanismo disciplinar de normatização pois os alunos são enquadrados de diversas maneiras: idade, conteúdo, série, entre outros critérios. $\mathrm{E}$, de certo modo, o professor possibilita esse funcionamento através da vigilância, do comando e da regulação das atividades, permitindo o "bom" funcionamento escolar.

Me relaciono bem. Digo assim: Se a gente tá indo bem ou não. Que aí é que ela fica de olho para ver como a gente está se saindo. Se a gente tá fazendo um jogo, um jogo digamos assim, limpo. Se a gente tá fazendo um jogo limpo, uma atividade amigável, tipo seja se tratando do assunto que ela... Se tratando do assunto que foi escolhido (ENTREVISTA ALUNO B).

Do mesmo modo, a monitora também faz parte dessa vigilância, pois está acompanhando o aluno para vigiá-lo, para colocá-lo dentro das regras instituídas pela escola, as quais também são esperadas na sociedade. Através de uma cobrança para atitudes disciplinares, como o comportamento e cópia dos conteúdos, a monitora garante um sujeito enquadrado em padrões disciplinares. 
copiou e ele diz que sim. Mas, tem poucas linhas escritas no caderno. A monitora diz então que ele tem que fazer as tarefas para a próxima aula. Do contrário, ela ficará decepcionada (DIÁRIO DE CAMPO, 5 jun. 2014).

É possível observar na passagem acima que o monitor exerce uma função disciplinadora e normatizadora, mas também normalizadora, já que faz com que 0 aluno em processo de inclusão copie os mesmos conteúdos e tenha um avanço o mais próximo do padrão instituído como normal. Contudo, ele ainda é o outro, ainda está sendo visto como aquele para o qual as práticas includentes se destinam e isso já marca sua identidade de outro. Embora ele esteja realizando, aparentemente, as mesmas tarefas que os colegas, ele ainda é visto como 0 anormal. Contudo, o desejo da escola, do professor, e do monitor desses alunos analisados é o de que essas marcas sejam invisíveis a partir do fato dele, por exemplo, ter o caderno completo ou apresentar um comportamento considerado desejável nas aulas de Educação Física. Parece que, a partir do momento em que ele for capturado pelo arcabouço disciplinar da escola, ele deixará de ser o outro e estará incluído. É nesse sentido que apontamos nossa problematização, discutindo o fato de que, apesar dos alunos serem capturados pelas práticas disciplinares e se comportarem como os outros, isso não garante sua inclusão. Ao contrário, evidencia os mecanismos de in/exclusão presentes nessas relações.

\title{
3.3. Normalização do considerado anormal
}

Na nossa terceira e última categoria de análise abordaremos os processos de normalização realizados nos alunos com deficiência durante as aulas de Educação Física. A partir da análise do material, podemos perceber que a escola está preocupada em guiar a conduta do aluno para que ela seja a mais adequada possível com o ambiente em que está inserido. Isso se materializa através da cópia de conteúdos, do respeito aos horários e da conduta considerada adequada para uma sociedade normal. Dessa forma, a escola cumpre o seu papel, como afirma Veiga-Neto (2003),

[...] como instituição envolvida na civilidade, ou seja, envolvida na transformação dos homens: de selvagens em civilizados. A escola como lugar capaz de arrancar cada um de nós - e, assim, arrancar a sociedade de que fazemos parte - da menoridade e nos lançar num estágio de vida mais evoluído, criando uma sociedade formada por cidadãos que, por estarem na "mesma cidade", estão num ambiente comum e, por isso, têm de aprender a viver minimamente se tolerando, em cooperação mútua e sem se barbarizarem. Esse talvez seja o sentido mais radical da escola moderna (VEIGA-NETO, 2003, p. 104-105.).

O Aluno $\mathrm{B}$, quando questionado se a monitora o acompanha nas aulas, responde da seguinte forma:

\begin{abstract}
Me acompanha sim, me acompanha sim. Sim. Às vezes quando ela escreve do mesmo. Às vezes eu escrevo assim o que tá passando no quadro assim, o que a pessoa tá passando no quadro. Ou me acompanha. Ou me acompanha assim, tipo vendo eu fazer as atividades físicas. Toda a quinta-feira é assim (ENTREVISTA DO ALUNO B).
\end{abstract}

Percebemos uma prática normalizadora, por tentar enquadrar todos os alunos no mesmo ritmo e na mesma série, mesmo que para isso seja necessário não respeitar o tempo do aluno e copiar o conteúdo para ele. Ao mesmo tempo, os alunos têm seus monitores como uma referência, como alguém a quem também devem mostrar seus êxitos. Ou seja, é uma tentativa 
de normalizar os sujeitos. No caso do Aluno C, a monitora age da seguinte forma: "No final da aula, Aluno $\mathrm{C}$ vem falar com a monitora para ver se ela gostou da participação dele e ela 0 elogia (DIÁRIO DE CAMPO, 15 jul. 2014)".

É necessário destacar que a inclusão pode parecer algo automático, mas é no processo para além do espaço que as dificuldades tornam-se visíveis. A partir disso, existem controvérsias que devem ser problematizadas, como, por exemplo, se a ocupação de um mesmo espaço resolvesse todos os problemas.

A Educação Física é uma disciplina que está atrelada aos objetivos da escola e da sociedade. Nesse panorama, ela também colabora com o imperativo de inclusão já estabelecido e trabalha para aproximar os sujeitos e torná-los mais governáveis. Contudo, o que queremos debater é que isso não deve ser visto como algo natural, mas devemos olhar para os entremeios desse processo e perceber o que realmente acontece no cotidiano desses alunos incluídos. Devemos olhar a prática sem considerá-la a priori benevolente, como acontece em muitos casos. Podemos perceber isso na fala do aluno que incorpora um discurso politicamente correto.

Às vezes me sinto bem, outras me sinto assim: se a gente fez ou não, se a gente ganhou ou perdeu, não importa. Não importa se você venceu ou não, importa que você participou bem. Se você não foi melhor, tenta na próxima. Às vezes quando não me sinto bem, me sinto "um cara de um só", seja porque não fizesse bem ou porque perdesse num jogo amigável para o time adversário do teu amigo da mesma sala ou de outras salas ou turmas (ENTREVISTA DO ALUNO B).

Essa incorporação do discurso politicamente correto, como "não importa se você venceu, importa que participou", é benéfica para a escola, pois isso significa que ela cumpriu o seu papel na inclusão desse aluno. A Educação Física, assim como as outras disciplinas e o ambiente escolar, também colabora para que o aluno incorpore essas práticas moralistas do que é certo ou errado e por isso se aproxima de uma conduta considerada adequada, normalizando esses sujeitos.

Podemos observar que esse discurso está presente na fala do Aluno B quando este fala sobre sua dificuldade em se relacionar com os colegas nas atividades competitivas na aula de Educação Física. Esse relato não é neutro, pois para que ele saiba que o comportamento não é adequado teve que passar por um processo de normalização.

Às vezes, às vezes eu tenho dificuldade tipo assim, quando tá nervoso. De vez em quando as atividades que o pessoal tá passando, se vai tentar ou não. Ou se seja numa do tipo entre amigos. É que assim ó. Por quê? Assim. Às vezes não se sabe, às vezes não se sabe assim. Às vezes não se sabe o que pode acontecer, se pode acontecer. Se tá ganhando ou se tá perdendo ou se tá empatada. Às vezes não se sabe, a gente pode saber assim, se um acertou. Com os erros, todo mundo aprende (ENTREVISTA DO ALUNO B).

O Aluno B percebe esses efeitos de normalização de forma tênue na aula de Educação Física, no entanto indica ter dificuldade com isso, pois ele se preocupa com o comportamento que deve desempenhar durante a aula para que se enquadre adequadamente nesse espaço.

Outro aspecto que gostaríamos de destacar é a preocupação com os comportamentos inadequados que os alunos anormais possam vir a executar e como estes passam a ter um tom mais grave que o do aluno regular. Como podemos perceber na passagem abaixo, 0 aluno anormal derruba um colega e a situação é bem mais tensa de que quando ele foi derrubado por 
este mesmo colega normal, como já foi visto anteriormente nesse artigo.

O mesmo colega que "provocou" a queda de Aluno B segue a provocá-lo. E, em uma disputa pela bola, esse colega cai no chão, perto de Aluno B. Os outros colegas ficam olhando, o aluno fica no chão reclamando de dor no ombro e no cotovelo. E a monitora grita para Aluno B pedir desculpas e ele pede. Logo após, a monitora quer tirar ele do jogo, alegando que está passando dos limites. Aluno $B$ reclama $e$ entra na sala de materiais, onde a professora dá uma bola de basquete para ele. A monitora diz que não, mas a professora diz que cuida. E Aluno B fica junto com os outros colegas jogando para tentar fazer cesta (DIÁRIO DE CAMPO, 22 maio 2014).

As atitudes em torno dos sujeitos anormais na tentativa de adequá-los respondem a um objetivo social de tentar melhor governá-los e conduzi-los para dentro de uma norma estabelecida. O monitor não entra por acaso na escola, ele é mais um para vigiar e tentar enquadrar esse sujeito para que os comportamentos desviem o mínimo possível. Contudo, embora haja um esforço para mostrar que esses sujeitos estão incluídos, apagando as marcas de suas anormalidades, essa operação evidencia a exclusão presente na instituição escolar e reafirma que se trata de um processo de in/exclusão.

\section{CONSIDERAÇÕES FINAIS}

A partir das categorias apresentadas, podemos perceber que o imperativo da inclusão não pode ser naturalizado, pois estar na escola não resolverá os problemas de exclusão existentes. Este é um tema complexo que envolve vários aspectos sociais, políticos e econômicos e que não será resolvido com a ocupação de um espaço físico. Ou seja, estar no ambiente escolar não garante a inclusão do aluno com deficiência, como foi possível perceber nas passagens relatadas. Pois, como destacou Lopes e Fabris (2013), "[...] embora o fortalecimento das representações seja uma condição necessária para que a inclusão se estabeleça de outras formas, essa não é condição suficiente para uma vida com dignidade para todos ou para eliminar a ameaça constante da in/exclusão" (LOPES; FABRIS, 2013, p. 12).

Além disso, percebemos que tanto os professores como os monitores auxiliam nos processos de normatização e de normalização do aluno para que possam atingir aos objetivos da instituição escolar, que é enquadrar todos dentro de uma mesma lógica, adequando as condutas. Nessa perspectiva, nos questionamos sobre o lugar do ensino dos saberes escolares, pois a preocupação está voltada para a condução da conduta e não para os processos de ensino-aprendizagem.

Contudo, consideramos que esse processo de inclusão escolar e, especificamente, de inclusão na Educação Física, possibilita experiências positivas aos educandos que interagem com seus colegas, com o professor e com o ambiente. Porém assinalamos que muito ainda precisa ser construído nessa relação que, por enquanto, está mais preocupada em normalizar os sujeitos.

Por fim, destacamos que a inclusão e os processos de normalização e normatização que ela desencadeia são muito importantes para a sociedade e para a escola, que com seus processos de disciplinamento e enquadramento auxiliam na condução das condutas. 0 que se procura é que os sujeitos se adequem a uma conduta social e entrem no jogo econômico. Para isso, hoje colocá-los sob a guarda da escola é um modo de garantir que suas condutas serão 
governadas. Todavia, como professoras, nos preocupamos com outros aspectos que ficam à margem quando a centralidade da escola direciona-se para conduzir a conduta do outro.

\section{REFERÊNCIAS}

FOUCAULT, Michel. Verdade e poder. In: FOUCAULT, M. Microfísica do poder. São Paulo: Graal, 1988. p. 35-54.

FOUCAULT, Michel. Vigiar e punir. 33. ed. Petrópolis: Vozes, 2007.

FOUCAULT, Michel. Segurança, território e população: 1977- 1978. São Paulo: Martins Fontes, 2008.

LOCKMANN, Kamila. Inclusão escolar: saberes que operam para governar a população. 2010. 130 f. Dissertação (Mestrado em Educação) - Programa de Pós-Graduação em Educação, Universidade Federal do Rio Grande do Sul, Porto Alegre, 2010.

LOPES, Maura Corcini. Políticas de inclusão e governamentalidade. Educação e Realidade, v. 34, n. 2, p. 153-169, maio/ago. 2009.

LOPES, Maura Corcini. Políticas de inclusão e governamentalidade. In: THOMA, A.S., HILLESHEIM, B. (Org.). Políticas de inclusão: gerenciando riscos e governando as diferenças. Santa Cruz do Sul: EDUNISC, 2011. p. 7-15.

LOPES, Maura Corcini. Norma, inclusão e governamentalidade neoliberal. In: BRANCO, Guilherme; VEIGA-NETO, Alfredo (Org.). Foucault, filosofia e política. Belo Horizonte: Autêntica, 2013. p. 283-298.

LOPES, Maura Corcini; FABRIS, Eli Henn. Inclusão e educação. Belo Horizonte: Autêntica, 2013.

LOPES, Maura Corcini; RECH, Tatiana Luiza. Inclusão, biopolítica e educação. Educação, v. 36, n.2, p. 210- 219, maio/ago. 2013.

MACHADO, Roseli Belmonte. Paraolimpíadas e políticas de inclusão: novas formas de governo dos corpos. Revista Querubim, v. 2, n. 15, p. 129 -136, out. 2011.

MANDARINO, Claudio Marques. Inclusão e diferença: tensionamentos e debates na formação acadêmica. In: CONGRESSO SULBRASILEIRO DE CIÊNCIAS DO ESPORTE, 5., 2010, Itajaí.

Anais... Itajaí: UIVALI, 2010. Disponível em: <http://congressos.cbce.org.br/index.php/sulbrasileiro/ vcsbce/paper/viewFile/2029/1059>. Acesso em: 15 dez. 2015.

ORGANIZAÇÃO DAS NAÇÕES UNIDAS PARA A EDUCAÇÃO, CIÊNCIA E CULTURA. Declaração mundial sobre educação para todos: satisfação das necessidades básicas de aprendizagem. Jomtiem/Tailândia, 1990. Disponível em <http://unesdoc.unesco.org/images/0008/000862/086291por. pdf>. Acesso em: 20 dez. 2014.

SANTOS, Iolanda Montano. Inclusão escolar e a educação para todos. 212 f., 2010. Tese (Doutorado em Educação) - Faculdade de Educação, Universidade Federal Rio Grande do Sul, Porto Alegre, 2010.

SILVEIRA, Rosa Maria Hessel. A entrevista na pesquisa em educação - uma arena de significados. In: COSTA, Marisa Vorraber (Org.). Caminhos investigativos II: outros modos de pensar e fazer pesquisa em educação. Rio de Janeiro: Lamparina, 2007. p. 117-138.

THOMA, Adriana Silva; HILLESHEIM, Betina. (Org.). Políticas de inclusão: gerenciando riscos e governando as diferenças. Santa Cruz do Sul: EDUNISC, 2011.

VARELA, Julia. Categorias e espaços temporais e socialização escolar: do individualismo ao narcisismo. In: COSTA, Marisa Vorraber. (Org.) Escola básica na virada do século: cultura, política e currículo. São Paulo: Cortez, 1996. p. 73-106. 
VEIGA-NETO, Alfredo. Incluir para saber: saber para excluir. Pro-Posições, v. 12, n. 2-3, p. 35-36, jul./nov. 2001.

VEIGA-NETO, Alfredo. Foucault e a educação. Belo Horizonte: Autêntica, 2007.

VEIGA-NETO, Alfredo. Pensar a escola como uma instituição que pelo menos garanta a manutenção das conquistas fundamentais da Modernidade. In: COSTA, Marisa Vorraber (Org.). A escola tem futuro? Rio de Janeiro, DP\&A, 2003. p. 103-126.

VEIGA-NETO, Alfredo; LOPES, Maura Corcini. Inclusão como dominação do outro pelo mesmo. In: COLÓQUIO INTERNACIONAL MICHEL FOUCAULT, 7., 2011, São Paulo. Disponível em: <http:// www.fe.unicamp.br/TEMPORARIOS/veiga-neto-lopes-inclusao-como-dominacao.pdf>. Acesso em: 10 abr. 2014 